\title{
Calcium-influx increases SOD1 aggregates via nitric oxide in cultured motor neurons
}

\author{
Hyun-Jung Kim ${ }^{1}$, Wooseok $\mathrm{Im}^{2}$, Seungchan $\mathrm{Kim}^{3}$, \\ Sung Hun Kim ${ }^{4}$, Jung-Jun Sung ${ }^{2}$, Manho Kim ${ }^{2,5}$ \\ and Kwang-Woo Lee ${ }^{2}$
}

\author{
${ }^{1}$ School of Chemical and Biological Engineering \\ Institute of Chemical Processes \\ Seoul National University \\ Seoul 151-741, Korea \\ ${ }^{2}$ Department of Neurology \\ Seoul National University College of Medicine \\ Seoul 110-799, Korea \\ ${ }^{3}$ Seoul Science High School \\ Seoul 110-530, Korea \\ ${ }^{4}$ Department of Neurology \\ College of Medicine, Kangwon National University \\ Chuncheon 200-701, Korea \\ ${ }^{5}$ Corresponding author: Tel, 82-2-2072-2193; \\ Fax, 82-2-3672-7553; E-mail, kimmanho@ snu.ac.kr
}

Accepted 22 June 2007

Abbreviations: ALS, amyotrophic lateral sclerosis; nNOS, neuronal nitric oxide synthase; SOD1, superoxide dismutase type 1

\begin{abstract}
Familial amyotrophic lateral sclerosis (fALS) is caused by mutations in $\mathrm{Cu} / \mathrm{Zn}$-superoxide dismutase (SOD1), and SOD1 aggregation and calcium toxicity are involved in neuronal death. However, the effect of altered calcium homeostasis on the SOD1 aggregation is unknown. To investigate whether calcium triggers mutant SOD1 aggregation in vitro, human mutant SOD1 (G93A) was transfected into motor neuronal cell line (VSC 4.1 cells). These cells were then treated with calcium ionophore A23187 or agents that induce intracellular calcium release like cyclic ADP ribose, ryanodine or thapsigargin. A23187 was found to increase mutant SOD1 aggregation and neuronal nitric oxide synthase (nNOS) expression. Moreover, the NOS inhibitor (L-NAME) and a NO-dependent cyclic GMP cascade inhibitor (ODQ) reduced SOD1 aggregation, whereas an exogenous NO donor (GSNO) increased mutant SOD1 aggregation, which was also prevented by NOS or CGMP cascade inhibitor. Our data demonstrate that calcium-influx increases SOD1 aggregation by upregulating $\mathrm{NO}$ in cultured motor neuronal cells.
\end{abstract}

Keywords: amyotrophic lateral sclerosis; calcium; motor neuron disease; nitric oxide; nitric oxide synthase; superoxide dismutase

\section{Introduction}

Amyotrophic lateral sclerosis (ALS) is a neurodegenerative disease that causes loss of motor neurons in spinal cord, brain stem, and motor cortex. Moreover, one fifth of familial ALS (fALS) cases are associated with mutations in the gene encoding free-radical scavenging enzyme $\mathrm{Cu} / \mathrm{Zn}$ superoxide dismutase (SOD1) (Rosen et al., 1993), and SOD1 protein aggregation mediates motor neuronal degeneration in ALS (Cleveland, 1999). In addition, SOD1 aggregates have been observed in the neurons or astrocytes of transgenic mice expressing human mutant SOD1 (Bruijn et al., 1998), and Lewy body-like hyaline inclusions, containing SOD1 as a major component, were observed in fALS patients (Shibata et al., 1996). It has also been reported that mutant SOD1 aggregation triggers cytochrome $c$ release, and that this release leads to caspase-dependent cell death (Takeuchi et al., 2002).

Glutamate-induced excitotoxicity has also been implicated in the pathophysiology of ALS and has been reported in mutant SOD1 transgenic mice (Choi, 1988; Van Den Bosch et al., 2006). Spinal motoneuron excitotoxicity depends on calciumpermeable $\alpha$-amino-3-hydroxy-5-methyl-4-isoxazole propionic acid (AMPA) receptors, which are expressed in a subset of neurons, including spinal motoneurons (Kruman et al., 1999). Moreover, the absence of the GluR2 subunit in AMPA receptor renders the receptor calcium permeable (Hollmann and Heinemann, 1994), and reduced GluR2 mRNA editing efficiency and GluR2 subunit expression have been reported in motor neurons from human sporadic ALS patients (Kawahara et al., 2004) and from mutant SOD1 transgenic mice (Tortarolo et al., 2006). As spinal motor neurons are less able to buffer calcium level increases, due to a lack of calcium-chelating proteins like parvalbumin and calbindin D28K, excessive calcium-permeable glutamate receptor activation results in an intracellular calcium overload and motor neuronal death (Alexianu et al., 1994; Shaw and Eqqett, 2000). SOD1 mutation increases the vulnerability 
of motor neurons to excitotoxicity induced by altered calcium homeostasis (Kruman et al., 1999). Moreover, increased intracellular calcium triggers calpain (Rami et al., 1997) and neuronal nitric oxide synthase (nNOS) activation. However, the effect of increased intracellular calcium on the formation of mutant SOD1 aggregates is unknown. In this study, we investigated the mechanisms by which altered intracellular calcium homeostasis contributes to the formation of mutant SOD1 aggregates in cultured motor neuronal cells.

\section{Materials and Methods}

\section{Cell Culture}

VSC 4.1 (ventral spinal cord 4.1) is a motoneuronneuroblastoma hybrid cell line, a fusion product of neuroblastoma N18TG2 cells and dissociated embryonic rat ventral spinal cord cells [a gift from Dr. Appel SH, (Baylor College of Medicine, Houston)]. VSC 4.1 cells were grown in DMEM/ F-12 growth medium (Gibco, Grand Island, NY) containing Sato's components (Sigma, St. Louis, $\mathrm{MO})$ and $2 \%$ heat-inactivated newborn calf serum (HyClone, Logan, UT) on poly-(L-ornithine)-precoated culture dishes (Falcon, Franklin Lakes, NJ).

\section{Plasmid constructs and transfection}

pcDNA 3.1 vectors (Invitrogen, Carlsbad, CA) containing cDNA encoding wild type (WT) or mutant (G93A) human SOD1 were gifts from Dr. Lawrence J. Hayward (University of Massachusetts, Boston). WT and G93A SOD1 cDNA were cloned into the $B a m \mathrm{HI}$ and EcoRI sites of pcDNA3.1 vector. To induce the transient overexpressions of WT and G93A SOD1 protein, VSC4.1 cells were plated at 2 $\times 10^{5}$ cells per well in 24-well plates (Falcon) containing coverslips (Fisher Scientific, Pittsburgh, PA) coated with poly-L-ornithine. $5 \mu \mathrm{g}$ plasmid DNAs of the WT or G93A SOD1 were mixed with serum free media containing $25 \mu \mathrm{l}$ of Superfect (Qiagen, Valencia, CA), and incubated at room temperature for $10 \mathrm{~min}$.

After $3 \mathrm{~h}$ of treatment, media were replaced with fresh culture medium. Transfection efficiencies fell in the range $50-60 \%$.

\section{Calcium ionophore, intracellular calcium releasers, NO, and other agents treatment}

To investigate the effects of calcium influx on the formation of aggregates, $1 \mu \mathrm{M}$ of calcium mobilizer (4-bromo-calcium ionophore A23187, Sigma) was added to culture medium $24 \mathrm{~h}$ after transient transfection with the cDNAs of WT or G93A SOD1. In addition, other intracellular calcium release agents, i.e., $10 \mu \mathrm{M}$ cyclic ADP ribose, $10 \mathrm{nM}$ ryanodine, or $10 \mu \mathrm{M}$ thapsigargin were also added to the transfected cells. In order to determine the effects of exogenous nitric oxide (NO), $200 \mu \mathrm{M}$ S-nitrosoglutathione (GSNO, Sigma) was also treated using the above-described procedure. 1 $\mathrm{mM} \mathrm{N}{ }^{\omega}$-nitro-L-arginine methyl ester (L-NAME; a non-selective nitric oxide synthase inhibitor; Sigma) or $1 \mu \mathrm{M} 1 \mathrm{H}-[1,2,4]$ oxadiazolo-4, 3-aquinoxalin-1-one (ODQ; NO-dependent guanylyl cyclase cGMP cascade inhibitor; Sigma) was used to inhibit the effect of NO. In addition, $50 \mu \mathrm{M} z-$ VAD-fmk (a cell-permeable pancaspase inhibitor; Promega) or $5 \mu \mathrm{M}$ z-DEVD-fmk (a cell-permeable caspase 3 specific inhibitor; Calbiochem, San Diego, CA) was used to block caspase activation. $20 \mu \mathrm{M}$ of calpeptin (Calbiochem) or $10 \mu \mathrm{M}$ of ALLM (a calpain inhibitor II; Calbiochem) was used as calpain inhibitors.

These inhibitors were pretreated one hour before the treatment with 4-bromo-calcium ionophore A23187 or GSNO.

\section{Immunofluorescence staining and the quantitative assessment of cells containing aggregates}

Transfected cells grown on glass coverslips were fixed for 20 min with $4 \%$ paraformaldehyde in PBS at room temperature and rinsed briefly with PBS. After fixation, they were permeabilized in $0.2 \%$ Triton X-100 (Sigma) and treated with 4\% normal goat serum (Vector Laboratory, Burlingame, CA) for $1 \mathrm{~h}$. To investigate the expression of human SOD1 protein, cells were treated at $4^{\circ} \mathrm{C}$ overnight at a dilution of 1:300 with antibody specific to human SOD1 (Sigma). To induce SOD1 immunofluorescence, cells were incubated at a dilution of 1:300 with Bodipy FL anti-mouse IgG (Molecular Probes, Eugene, OR) at room temperature for $2 \mathrm{~h}$. The characteristics of SOD1 aggregates in cells were examined either under an Olympus fluorescence microscope or a confocal microscope Zeiss LSM 5 Pascal. Quantitative analysis of cells containing SOD1 aggregates was performed under a fluorescence microscope using a $20 \times$ objective. Over 200 transfected cells on duplicate coverslips were assessed in three independent experiments. The distribution of SOD1 in cells was categorized as diffuse or aggregated. Most immunoreactive protein in cell bodies was observed in aggregates (Figure 1A). To score cells with SOD1 aggregates, six random microscopic fields were counted per coverslip. The microscopic fields to measure were blindly selected in coded slides. The selected 
areas showing significant differences in total cell counts were excluded. Frequencies of intracytoplasmic aggregate-containing cells were defined as number of cells with aggregates divided by the number of SOD1-positive cells.

\section{SOD activity assays}

SOD activities were assayed as previously described (Misura and Fridovich, 1972). Activities were measured at $30^{\circ} \mathrm{C}$ by determining the rate inhibiting epinephrine auto-oxidation in $50 \mathrm{mM}$ sodium carbonate buffer $(\mathrm{pH} 10.2)$ and $30 \mu \mathrm{l} 10$ $\mathrm{mM}$ epinephrine to give a slope of 0.025 absorbance units $/ \mathrm{min}$ at $480 \mathrm{~nm}$. The amount of SOD in a sample required to inhibit the rate of epinephrine auto-oxidation by $50 \%$ was defined as one unit of activity, and is expressed in units/mg of protein.

\section{Western blot analysis}

Total proteins from transfected cells were extracted with RIPA buffer (25 mM Tris- $\mathrm{HCl}(\mathrm{pH} 7.4), 5 \mathrm{mM}$ EDTA, and $137 \mathrm{mM} \mathrm{NaCl}, 1 \%$ TritonX-100, $1 \%$ sodium deoxycholate, $0.1 \%$ SDS) containing protease inhibitor cocktail tablets (Roche, Mannheim, Germany). Protein concentrations were determined using the Bradford method (Bio-Rad, Richmond, CA) using BSA as a standard. Proteins $(30 \mu \mathrm{g} /$ lane) were separated in SDS-polyacrylamide separating gels and blotted onto nitrocellulose. Blots were probed overnight at $4{ }^{\circ} \mathrm{C}$ with anti-SOD 1 monoclonal antibody diluted to 1:500 (Sigma), anti-nNOS polyclonal antibody diluted 1:500 (Transduction Lab, Franklin lakes, NJ), or anti-nitrotyrosine antibody diluted 1:500 (Upstate, Charlottesville, VA), respectively. Anti- $\alpha$-tubulin monoclonal antibody (clone DM 1A; 1:500, Neomarker, Fremont, CA) was used to compare protein loadings. Bands were visualized by chemiluminescence (Supersignal, Pierce, Rockford, IL).

\section{Caspase 3 activity assays}

Caspase 3 activities were determined by following specific cleavage at the C-terminal of the aspartate residue of the amino acid sequence DEVD (AspGlu-Val-Asp) by caspase 3 . Cells $\left(2 \times 10^{6} /\right.$ dish $)$ plated on a $60-\mathrm{mm}$ dish (Falcon) were grown in culture medium until $80-90 \%$ confluent. Activity was measured using a Caspase ${ }^{\mathrm{TM}}$ assay system (Promega, Madison, WI), according to the manufacturer's instructions. In brief, treated cells were suspended in cell lysis buffer at $10^{6}$ cells $/ \mathrm{ml}$ and
A

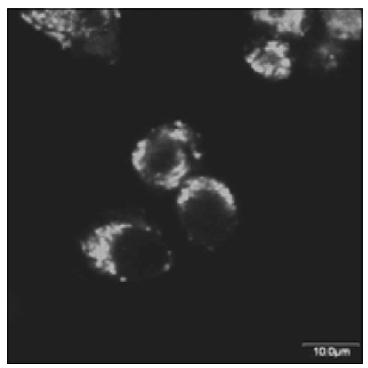

B

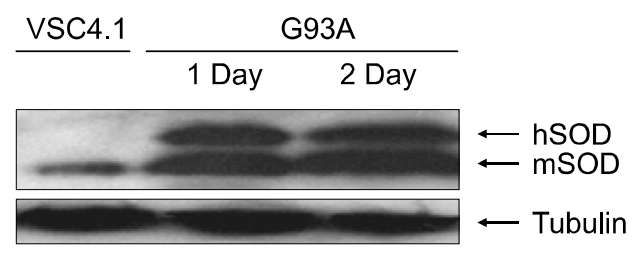

C

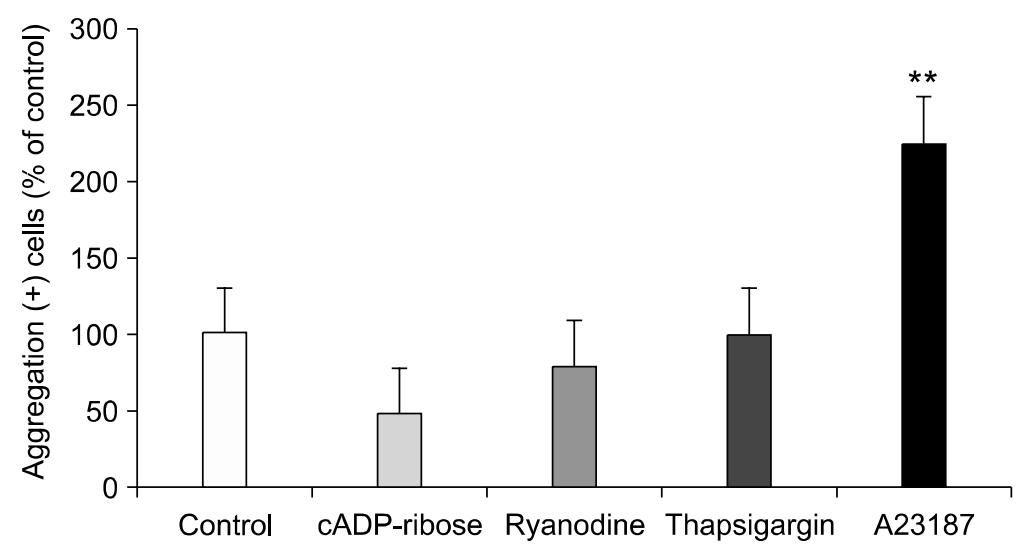

Figure 1. The expression of human mutant SOD1 in VSC 4.1 cells and aggregate formation after exposure to calcium modulators. (A) VSC 4.1 cells transfected with mutant G93A SOD1 showed dispersed or perinuclear aggregation $(\mathrm{bar}=10 \mu \mathrm{m})$. (B) Mutated human SOD1 (hSOD) G93A, was transfected, and its protein expression was confirmed in addition to mouse SOD1 (mSOD). (C) Treatment with $1 \mu \mathrm{M}$ A23187 (a 4-bromo-calcium ionophore) increased the number of cells containing G93A SOD1 aggregates, whereas other intracellular calcium release agents (10 $\mu \mathrm{M}$ cyclic ADP ribose, $10 \mathrm{nM}$ ryanodine, or $10 \mu \mathrm{M}$ thapsigargin) had no effect. (Data are means \pm SEM. ${ }^{* *} P<0.01$, versus the corresponding untreated controls or treated groups, as determined by the Student's $t$ test, $n=5$ ). 
then lysed by freezing and thawing. Equal concentrations of lysates were incubated for $4 \mathrm{~h}$ at $37^{\circ} \mathrm{C}$ with caspase assay buffer $(312.5 \mathrm{mM}$ HEPES, 31.25\% sucrose, 0.3125\% 3-[(3-cholamidopropyl)-dimethylammonio]-1 propane-sulfonate; CHAPS), DMSO, $10 \mathrm{mM}$ DTT and colorimetric substrate (Ac-DEVD-pNA). Absorbances were measured at $405 \mathrm{~nm}$.

\section{Statistical analysis}

Data are presented as means \pm SEM and were analyzed using the Student's $t$ test. Statistical significance was established at $P<0.05$. All experiments were repeated three times.

A

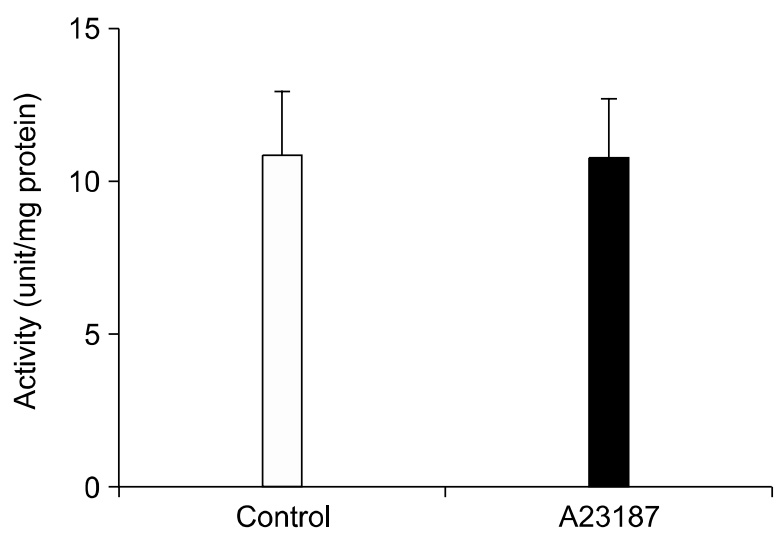

C

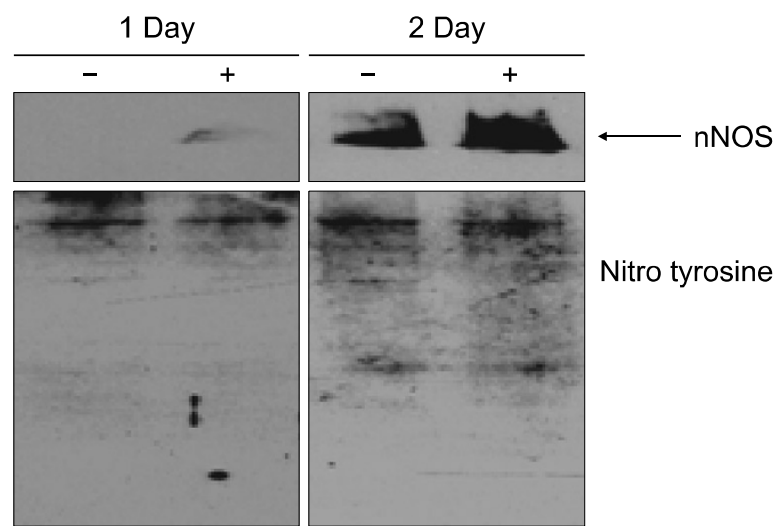

\section{Results}

\section{Mutant SOD1 aggregates in VSC4.1 cells}

In previous studies, aggregates of SOD1 were observed in the cytoplasm of cultured primary motor neurons expressing several different SOD1 mutants (Durham et al., 1997). In the present study, immunocytochemistry with antibody specific to human SOD1 revealed that mutant SOD1 aggregation was present in the cytoplasm of VSC 4.1 cells. Diffuse dispersed and perinuclear aggregations were frequently observed. The overexpression of human SOD1 protein was confirmed by Western blotting, and the size of protein different from that of endogenous mouse SOD1 in VSC 4.1 cells (Figure $1 \mathrm{~A}$ and $\mathrm{B}$ ).

B

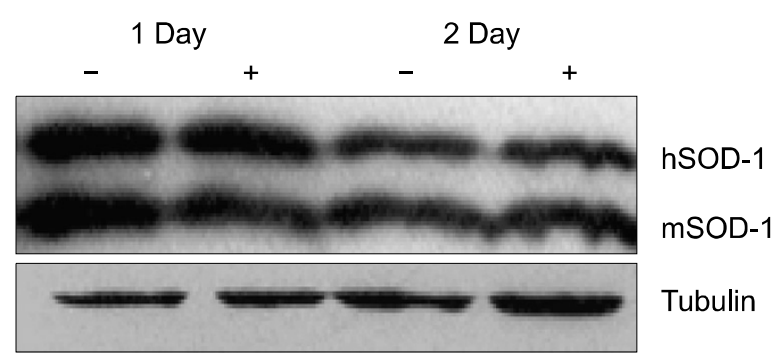

D

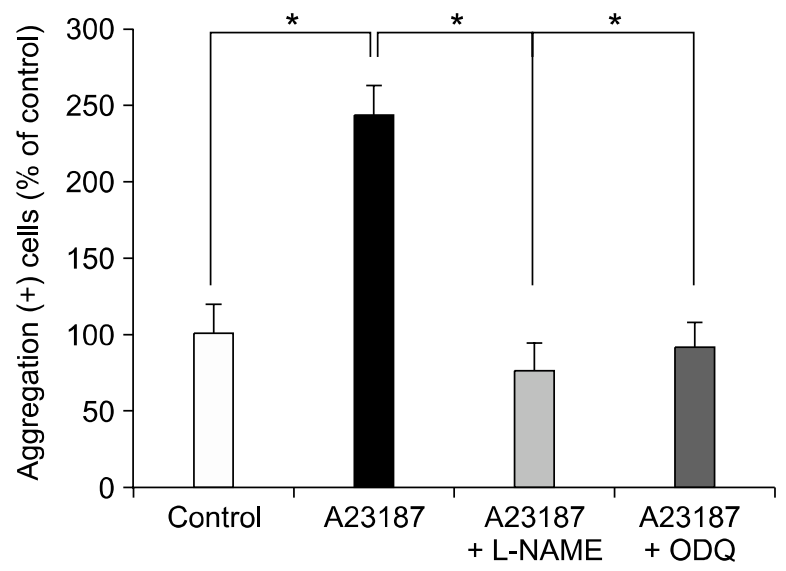

Figure 2. Calcium ionophore-induced SOD1 expression and activity, and the effect of NOS on SOD1 aggregation. (A) The SOD1 activities of mutant SOD1-transfected VSC 4.1 cells were unaffected by $1 \mu \mathrm{M}$ A23187, and (B) the expressions of SOD1 at $24 \mathrm{~h}$ or $48 \mathrm{~h}$ after $1 \mu \mathrm{M}$ A23187 treatment were also unchanged. (C) Expressions of nNOS were increased by $1 \mu \mathrm{M} \mathrm{A23187} \mathrm{but} \mathrm{the} \mathrm{expression} \mathrm{of} \mathrm{tyrosine-nitrated} \mathrm{protein} \mathrm{was} \mathrm{minimal.} \mathrm{(D)} \mathrm{Preincubation}$ of transfected cells with $1 \mathrm{mM} \mathrm{L-NAME} \mathrm{(a} \mathrm{non-selective} \mathrm{NOS} \mathrm{inhibitor)} \mathrm{or} 1 \mu \mathrm{M} O D Q$ (an NO-dependent guanylyl cyclase cGMP cascade inhibitor) prior to exposure to $1 \mu \mathrm{M} \mathrm{A} 23187$ decreased cell numbers showing SOD1 aggregation (means $\pm \mathrm{SEM}$ ). ${ }^{*} P<0.05$ versus untreated controls or the treated cells, as determined by the Student's $t$ test, $n=5$ ). 


\section{Calcium influx increased aggregate formation}

To determine whether an increase in intracellular calcium affects the formation of mutant SOD1 aggregates, the 4-bromo-calcium ionophore A23187 $(1 \mu \mathrm{M})$ or other intracellular calcium releasers, namely, cyclic ADP ribose $(10 \mu \mathrm{M})$, ryanodine (10 $n M)$, or thapsigargin $(10 \mu \mathrm{M})$ were added to cells after transfection with mutant SOD1. Treatment with A23187 increased SOD1 aggregation in cells, whereas the other intracellular calcium release agents did not $(P<0.01)$ (Figure 1C). To evaluate the possibility that A23187 alters the expression or activity of mutant SOD1, we examined levels of mutant SOD1 expression and activity. A23187 treatment did not change the expression level of SOD1 or its activity (Figure $2 \mathrm{~A}$ and $\mathrm{B}$ ).

A

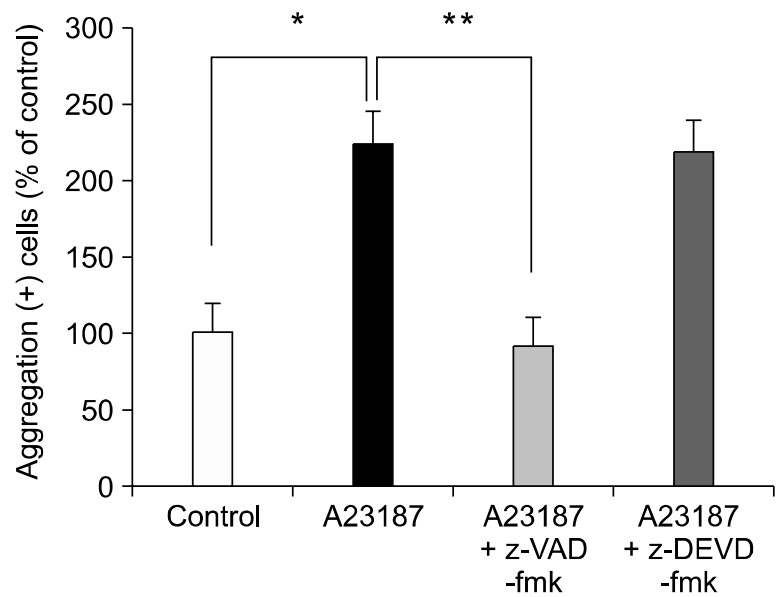

\section{C}

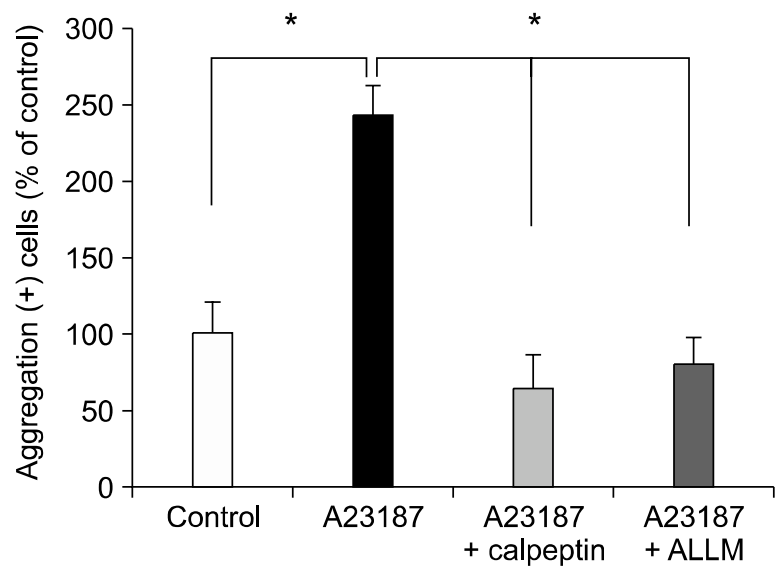

\section{Calcium influx-induced NO generation increased aggregate formation}

A23187 increased NO generation in VSC 4.1 cells expressing mutant SOD1 (Kim et al., 2002). We observed that A23187 treatment increased nNOS expression in cells containing transfected mutant SOD1 (Figure 2C). To further investigate whether NO is involved in SOD1 aggregation, the transfected cells were treated with $1 \mathrm{mM}$ L-NAME (a non-selective NOS inhibitor) or $1 \mu \mathrm{M}$ ODQ (a NO-dependent cyclic GMP cascade inhibitor), which attenuated aggregate formation $(P<0.05)$ (Figure 2D). Moreover, when cells were treated with exogenous GSNO it increased mutant SOD1 aggregation, and pretreatment with L-NAME and ODQ attenuated this effect of GSNO $(P<0.01)$ (Figure 4).

B

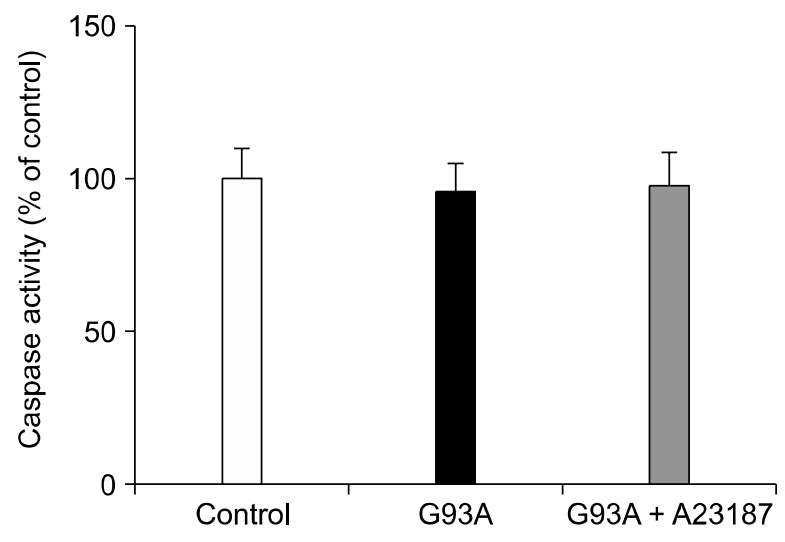

Figure 3. Effects of caspase and calpain on mutant SOD1 aggregation induced by calcium ionophore. (A) Preincubation of transfected cells with $50 \mu \mathrm{M} z$-VAD-fmk prior to exposure to $1 \mu \mathrm{M}$ A23187 decreased the number of cells containing aggregates, whereas $5 \mu \mathrm{M} z$-DEVD-fmk (a caspase 3 specific inhibitor) was ineffective. (B) Caspase 3 activities, as determined by Ac-DEVD-pNA cleavage (a colorimetric substrate) were not altered. (C) Pretreatment with calpain inhibitor $(20 \mu \mathrm{M}$ calpeptin) or calpain inhibitor II (10 $\mu$ M ALLM) reduced the increased number of cells containing aggregates after $1 \mu \mathrm{M} \mathrm{A23187} \mathrm{treatment} \mathrm{(the} \mathrm{data}$ shown are means \pm SEM). ${ }^{* *} P<0.01,{ }^{*} P<0.05$, versus the corresponding untreated controls or treated groups, as determined by the Student's $t$ test, $n=5$ ). 


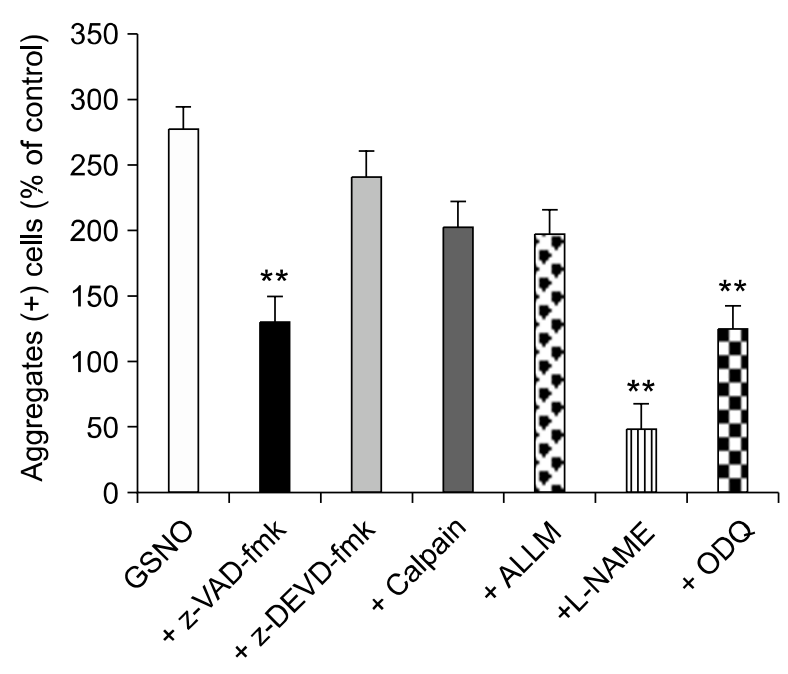

Figure 4. Effects of NO on the formation of mutant SOD1 aggregates in VSC 4.1 cells. (A) $200 \mu \mathrm{M}$ GSNO treatment increased the number of cells containing aggregates. Preincubation with $50 \mu \mathrm{M} z-V A D-f m k, 1 \mathrm{mM}$ L-NAME, or $1 \mu \mathrm{M} O D Q$ inhibited the increased aggregate formation after $200 \mu \mathrm{M}$ GSNO treatment, but $5 \mu \mathrm{M} z$-DEVD-fmk or calpain inhibitors $(20$ $\mu \mathrm{M}$ calpeptin or $10 \mu \mathrm{M}$ ALLM) were ineffective (Data shown are means \pm SEM. ${ }^{* *} P<0.01$, versus the corresponding untreated controls or treated groups, as determined by the Student's $t$ test, $n=5$ ).

\section{Calpain or caspase activation and aggregate formation}

The formation of mutant SOD1 aggregates has been previously linked with apoptotic cell death (Durham et al., 1997). Thus, we evaluated the involvements of caspase and calpain on SOD1 aggregate formation. A23187-induced mutant SOD1 aggregation was suppressed by z-VAD-fmk (a broad-spectrum caspase inhibitor), but not by z-DEVD-fmk (a caspase 3 inhibitor) (Figure 3A). Moreover, the activation of caspase 3 was not altered by calcium ionophore treatment (Figure 3B). Calpeptin or ALLM (both calpain inhibitors) reduced mutant SOD1 aggregation $(P<0.05)$ (Figure $3 C$ ), but aggregation induced by exogenous NO was not attenuated by these calpain inhibitors (Figure 4).

\section{Discussion}

The results obtained during the present study demonstrate that calcium-influx, not induced by endogenous calcium releasers, increases the formation of mutant SOD1 aggregates via NO production.

A shared histological feature of many neurodegenerative diseases is the accumulation of misfolded proteins that trigger cell death signaling pathway (Kang et al., 2007). Calcium-influx in- duced by motoneuronal AMPA receptors was found to promote the misfolding of mutant SOD1 protein and neuron death (Roy et al., 1998; Tateno et al., 2004), and the inhibition of L-type voltagegated calcium channels or NMDA receptors partially prevented the aggregation and toxic effect of mutant SOD1 (Roy et al., 1998). Calcium ionophore has been known to potentiate a response of neuron to NMDA (Markram and Segal, 1991). In addition, calcium ionophore treatment was found to lead to an increase in cytosolic calcium by influx from the extracellular environment (Reed and Lardy, 1972; Qian et al., 1999) and efflux from vesicles in the endoplasmic reticulum (ER), and thus, this ionophore could be used to mimic the effects of $\mathrm{IP}_{3}$ (Pressman, 1976). In the present study, only the calcium ionophore A23187 increased aggregate formation. The other intracellular calcium releasers, namely, cyclic ADP ribose, ryanodine, and thapsigargin did not affect SOD1 aggregation, demonstrating that calcium-influx plays a primary role in aggregate formation, whereas endogenous calcium release does not. Exogenous calcium-influx does not affect SOD1 enzyme activity or protein expression according to our data, which suggests that aggregate formation is not mediated by an altered SOD1 protein level or SOD1 activity.

Oxidative stress resulting from an increased intracellular calcium level induced the misfolding of SOD1 within motoneurons (Carriedo et al., 2000; Tateno et al., 2004). A cytoplasmic calcium overload can increase the production of reactive oxygen species via several mechanisms, e.g., the conversion of xanthine dehydrogenase to xanthine oxidase (Atlante et al., 1997), the activation of $\mathrm{PLA}_{2}$ (Chan and Fishman, 1980), superoxide production by mitochondria (Castilho et al., 1995), and the activation of NOS (Yun et al., 1996). Moreover, it was found that calcium influx via calcium ionophore stimulated NO production by calmodulin-dependent constitutive NOS (Markram and Segal, 1991). Previously, we showed that calcium ionophore increased NO generation significantly more than endogenous calcium release agents in motor neuronal cells expressing mutant SOD1 (Kim et al., 2002). In the present study, we found that nNOS is involved in calcium influxinduced aggregate formation. nNOS is constitutively expressed in neurons and activated by intracellular calcium upregulation (Blottner and Luck, 2001). Alterations in nNOS expression have also been reported in ALS (Anneser et al., 2001; Guegan and Przedborski, 2003). Treatment with NOS inhibitor decreased aggregate formation in cells containing mutant SOD1 (Hyun et al., 2003). 
Moreover, the co-localization of NOS and SOD1 was observed in neurofilament aggregates in fALS, and sequestration of nNOS to neurofilament aggregates enhanced NMDA-mediated calcium influx (Sanelli et al., 2004). However, the underlying mechanism as to how NOS increases aggregation formation is unknown. In the present study, the formation of SOD1 aggregates was attenuated by inhibiting NOS or the NO-dependent guanylyl cyclase cGMP cascade, which indicates that calcium influx-induced SOD1 aggregation, is mediated by NO.

In the present study, it was found that caspase or calpain is also involved in aggregate formation. Cultured motor neurons expressing mutant SOD1 and positive for apoptosis also contained SOD1 aggregates (Durham et al., 1997). Moreover, motor neuron death in ALS was found to be associated with the activations of various caspases, e.g., caspase-1, caspase- 3 and caspase- 9 (Ekegren et al., 1999; Li et al., 2000; Pasinelli et al., 2000). Increased aggregation by calcium influx can be attenuated by treating with z-VAD-fmk. However, z-DEVD-fmk was not effective and the activity of caspase 3 was unchanged in cells containing mutant SOD1 aggregates, which suggests that caspases other than caspase 3 may mediate aggregate formation. In addition, we observed that calpain inhibition was also effective at preventing calcium influx-induced SOD1 aggregation. Calpains are ubiquitously expressed in various cell types, including motoneurons (Suzuki et al., 1987), and may be activated in the presence of elevated levels of intracellular calcium or by autolytic processing, to cleave many cellular targets, such as, transcription factors, and signal transduction and cytoskeletal proteins. Calpains also activate the caspases that mediate apoptosis by triggering the degradation of the cytochrome c-binding protein apoptotic protease activating factor-1 (apaf-1) (Roberts-Lewis et al., 1993; Reimertz et al., 2001). Our data suggest that calcium influx induced calpain activation and that it played a role in the formation of mutant SOD1 aggregates.

Chronic exposure to glutamate increased the number of non-motor neurons expressing nNOS. It has been reported that under pathological conditions, reactive astrocytes or activated microglial cells produces NO, which has a toxic effect on surrounding cells (Nathan and Xie, 1994). In the present study, it was found that exogenous NO increases mutant SOD1 aggregation. However, unlike calcium influx-induced mutant SOD1 aggregation, calpain inhibitors did not attenuate exogenous NO-induced aggregation. The above findings suggest that extracellular NO upregulation may have a toxic effect and induce the formation of mutant SOD1 aggregates via a mechanism that differs from NO formation by calcium influx. Further studies are needed to verify our findings.

\section{Acknowledgments}

This study was supported by the Health 21 R\&D Project (A040042), FPR05C2-010, and R01-2006-000-10223-0 From the Basic Science and Engineering Foundation Fund.

\section{References}

Alexianu ME, Ho BK, Mohamed AH, La Bella V, Smith RG, Appel SH. The role of calcium-binding proteins in selective motoneuron vulnerability in amyotrophic lateral sclerosis. Ann Neurol 1994;36:846-58

Anneser JM, Cookson MR, Ince PG, Shaw PJ, Borasio GD. Glial cells of the spinal cord and subcortical white matter up-regulate neuronal nitric oxide synthase in sporadic amyotrophic lateral sclerosis. Exp Neurol 2001;171:418-21

Atlante A, Gagliardi S, Minervini GM, Ciotti MT, Marra E, Calissano P. Glutamate neurotoxicity in rat cerebellar granule cells: a major role for xanthine oxidase in oxygen radical formation. J Neurochem 1997;68:2038-45

Blottner D, Luck G. Just in time and place: NOS/NO system assembly in neuromuscular junction formation. Microsc Res Tech 2001;55:171-80

Bruijn LI, Houseweart MK, Kato S, Anderson KL, Anderson SD, Ohama E, Reaume AG, Scott RW, Cleveland DW. Aggregation and motor neuron toxicity of an ALS-linked SOD1 mutant independent from wild-type SOD1. Science 1998;281:1851-4

Carriedo SG, Sensi SL, Yin HZ, Weiss JH. AMPA exposure induce mitochondrial $\mathrm{Ca}(2+)$ overload an $\mathrm{ROS}$ generation in spinal motor neurons in vitro. J Neurosci 2000;20:240-50

Castilho RF, Kowaltowski AJ, Meinicke AR, Bechara EJ, Vercesi $A E$. Permeabilization of the inner mitochondrial membrane by calcium ions is stimulated by t-butyl hydroperoxide and mediated by reactive oxygen species generated by mitochondria. Free Radic Biol Med 1995;18: 479-86

Chan PH, Fishman RA. Transient formation of superoxide radicals in polyunsaturated fatty acid-induced brain swelling. J Neurochem 1980;35:1004-7

Choi DW. Glutamate neurotoxicity and diseases of the nervous system. Neuron 1988;1:623-34

Cleveland DW. From Charcot to SOD1: mechanisms of selective motor neuron death in ALS. Neuron 1999;24:51520

Durham HD, Roy J, Dong L, Figlewicz DA. Aggregation of mutant $\mathrm{Cu} / \mathrm{Zn}$ superoxide dismutase proteins in a culture model of ALS. J Neuropathol Exp Neurol 1997;56:523-30 
Ekegren T, Grundstrom E, Lindholm D, Aquilonius SM. Upregulation of Bax protein and increased DNA degradation in ALS spinal cord motor neurons. Acta Neuol Scand 1999; 100:317-21

Guegan C, Przedborski S. Programmed cell death in amyotrophic lateral sclerosis. J Clin Invest 2003;111:153-61

Hollmann M, Heinemann S. Cloned glutamate receptors. Annu Rev Neurosci 1994;17:31-108

Hyun DH, Lee M, Halliwell B, Jenner P. Proteasomal inhibition causes the formation of protein aggregates containing a wide range of proteins, including nitrated proteins. J Neurochem 2003;86:363-73

Kang BS, Ahn JY, Kim MK, Kim HJ, Kang L, Lim HC, Park KS, Lee JS, Seo JS, Cha CI, Kim SU, Park YJ, Kim M. Heat shock protein 70 alters the endosome-lysosomal localization of huntingtin. Exp Mol Med 2007;39:38-46

Kawahara Y, Ito K, Sun H, Aizawa H, Kanazawa I, Kwak S. Glutamate receptors: RNA editing and death of motor neurons. Nature 2004;427:801

Kim HJ, Kim M, Kim SH, Sung JJ, Lee KW. Alteration in intracellular calcium homeostasis reduces motor neuronal viability expressing mutated $\mathrm{Cu} / \mathrm{Zn}$ superoxide dismutase through a nitric oxide/guanylyl cyclase cGMP cascade. Neuroreport 2002;13:1131-5

Kruman II, Pedersen WA, Springer JE, Mattson MP. ALS-linked Cu/Zn-SOD1 mutation increases vulnerability of motor neurons to excitotocity by a mechanism involving increased oxidative stress and perturbed calcium homeostasis. Exp Neurol 1999;160:28-39

Li M, Ona VO, Guegan C, Chen M, Jackson-Lewis V, Andrews LJ, Olszewski AJ, Stieg PE, Lee JP, Przedborski S, Friedlander RM. Functional role of caspase- 1 and caspase-3 in an ALS transgenic mouse model. Science 2000;288: 335-9

Markram H, Segal M. Calcimycin potentiates responses of rat hippocampal neurons to N-metyl-D-aspartate. Brain Res 1991;540:322-4

Misura HP, Fridovich I. The role of superoxide anion in the autoxidation of epinephrine and a simple assay for superoxide dismutase. J Biol Chem 1972;247:3170-5

Nathan C, Xie QW. Nitric oxide synthases: roles, tolls, and controls. Cell 1994;78:915-8

Pasinelli P, Houseweart MK, Brown RH Jr, Cleveland DW. Caspase- 1 and -3 are sequentially activated in motor neuron death in $\mathrm{Cu}, \mathrm{Zn}$ superoxide dismutase-mediated familial amyotrophic lateral sclerosis. Proc Natl Acad Sci USA 2000; 97:13901-6

Pressman BC.Biological applications of ionophores. Ann Rev Biochem 1976;45:501-30

Qian T, Herman B, Lemasters JJ. The mitochondral permeability transition mediates both necrotic and apoptotic death of hepatocytes exposed to Br-A23187. Toxicol Appl Pharmacol 1999;154:117-25

Rami A, Ferger D, Krieglstein J. Blockade of calpain proteolytic activity rescues neurons from glutamate excito- toxicity. Neurosci Res 1997;27:93-7

Reed PW, Lardy HA. A23187: A divalent cation ionophore. J Biol Chem 1972;247:6970-7

Reimertz C, Kogel D, Lankiewicz S, Poppe M, Prehn JH. $\mathrm{Ca}(2+)$-induced inhibition of apoptosis in human $\mathrm{SH}-\mathrm{SY} 5 \mathrm{Y}$ neuroblastoma cells: degradation of apoptotic protease activating factor-1 (APAF-1). J Neurochem 2001;78:125666

Roberts-Lewis JM, Marcy VR, Zhao Y, Vaught JL, Siman R, Lewis ME. Aurintricarboxylic acid protects hippocampal neurons from NMDA- and ischemia-induced toxicity in vivo. J Neurochem 1993;61:378-81

Rosen DR, Siddique T, Patterson D, Fiqlewicz DA, Sapp P, Hentati A, Donaldson D, Goto J, O'Regan JP, Denq HX et al. Mutations in $\mathrm{Cu} / \mathrm{Zn}$ superoxide dismutase gene are associated with familial amyotrophic lateral sclerosis. Nature 1993;362:59-62

Roy J, Minotti S, Dong L, Figlewicz DA, Durham HD. Glutamate potentiates the toxicity of mutant $\mathrm{Cu} / \mathrm{Zn}$ superoxide dismutase in motor neurons by postsynaptic calcium-dependent mechanisms. J Neurosci 1998;18:967384

Sanelli TR, Sopper MM, Strong MJ. Sequestration of nNOS in neurofilamentous aggregate bearing neurons in vitro leads to enhanced NMDA-mediated calcium influx. Brain Res 2004;1004:8-17

Shaw PJ, Eqqett CJ. Molecular factors underlying selective vulnerability of motor neurons to neuro degeneration in amyotrophic lateral sclerosis. J Neuol 2000;247 suppl 1: I17-27

Shibata N, Asayama K, Hirano A, Kobayashi M. Immunohistochemical study on superoxide dismutases in spinal cords from autopsied patients with amyotrophic lateral sclerosis. Dev Neurosci 1996;18:492-8

Suzuki K, Imajoh S, Emori Y, Kawasaki H, Minami Y, Ohno S. Calcium-activated neutral protease and its endogenous inhibitor. Activation at the cell membrane and biological function. FEBS Lett 1987;220:271-7

Takeuchi H, Kobayashi Y, Ishigaki S, Doyu M, Sobue G. Mitochondrial localization of mutant superoxide dismutase 1 triggers caspase-dependent cell death in a cellular model of familial amyotrophic lateral sclerosis. J Biol Chem 2002;277: 50966-72

Tateno M, Sadakata H, Tanaka M, Itohara S, Shin RM, Miura M, Masuda M, Aosaki T, Urushitani M, Misawa H, Takahashi R. Calcium-permeable AMPA receptors promote misfolding of mutant SOD1 protein and development of amyotrophic lateral sclerosis in a transgenic mouse model. Hum Mol Genet 2004;13:2183-96

Tortarolo M, Griqnaschi G, Calvaresi N, Zennaro E, Spaltro G, Colovic M, Fracasso C, Guiso G, Elqer B, Schneider H, Seilheimer B, Caccia S, Bendotti C. Glutamate AMPA receptors change in motor neurons of SOD1G93A transgenic mice and their inhibition by a noncompetitive antagonist ameliorates the progression of amyotrophic lateral sclerosis-like disease. J Neurosci Res 2006;83:134-46 
Van Den Bosch L, Van Damme P, Boqaert E, Robberecht W. The role of excitotoxicity in the pathogenesis of amyotrophic lateral sclerosis. Biochim Biophys Acta 2006;1762:1068-82
Yun HY, Dawson VL, Dawson TM. Neurobiology of nitric oxide. Crit Rev Neurobiol 1996;10:291-316 